\title{
Perancangan Alat Penilaian untuk Pengembangan TPS Menjadi TPS 3R Di Wilayah Perencanaan IV Kota Bogor
}

\author{
ANTON ZACHARIA SUHERDY, SITI AINUN ,NICO HALOMOAN \\ Jurusan Teknik Lingkungan, FakultasTeknik Sipil dan Perencanaan, ITENAS \\ Email : anton.suherdi@gmail.com
}

\begin{abstract}
ABSTRAK
Tahun 2016, Kota Bogor dibagi menjadi 4 Wilayah Perencanaan dalam pengelolaan sampah. Lokasi yang dipilih adalah Wilayah Perencanaan IV, karena kodisi pada lokasi tersebut merupakan permukiman kumuh yang pengelolaannya masih menggunakan sistem kumpul-angkut-buang. Oleh karena itu, agar sampah dapat dikelola dengan adanya pengurangan sampah maka diperlukan TPS berbasis $3 R$ sehingga dapat mengurangi beban sampah di TPA. Perancangan alat penilaian disusun dengan tujuan untuk mengetahui kondisi eksisting TPS dan perilaku masyarakat dalam menangani sampah di sekitar TPS yang ada agar dapat dikembangkan menjadi TPS $3 R$ di Wilayah Perencanaan IV. Tahapan perancangan alat penilaian mengacu pada Buku Pedoman Umum 3R Pemukiman, dan Permen PU Nomor 3 tahun 2013. Selanjutnya mengumpulkan data sekunder, penilaian terhadap TPS yang dikelompokkan menjadi 3 aspek. Adapun pembagian aspek tersebut yaitu aspek lokasi, aspek fasilitas, dan aspek kegiatan yang ada di TPS serta dibagi menjadi 5 sub aspek, 21 indikator dan 34 pertanyaan. Penilaian PSM ( Peran Serta Masyarakat) dikelompokkan menjadi 3 aspek, yaitu aspek peran serta masyarakat, aspek pembiayaan, dan aspek kelembagaan serta dibagi menjadi 6 sub aspek dan 8 pertanyaan. Pada penilaian TPS pembobotan menggunakan skala Likert dengan skala pembobotan untuk TPS dari hasil penilaian adalah 76 - 100 kategori I (sudah menjadi TPS 3R), 51 75 kategori II (TPS berpotensi tinggi menjadi TPS 3R), 26 - 50 kategori III (TPS berpotensi sedang menjadi TPS 3R), 0 - 25 kategori IV (TPS berpotensi kecil menjadi TPS 3R). Sedangkan untuk penilaian PSM mempunyai range nilai tinggi $(68$ - 100), sedang $(34$ - 67), rendah $(0$ - 33). Jumlah responden untuk penilaian PSM yaitu 20 rumah dengan terdiri dari 8 pertanyaan, ditentukan dengan rumus Slovin dengan jumlah penduduk sebanyak 103.389 jiwa dan tingkat error sebesar 10\%. Jumlah TPS yg ada di lokasi perencanaan berjumlah 10.
\end{abstract}

Kata kunci: Alat penilaian, TPS, PSM, Wilayah Perencanaan IV, Kota Bogor. 


\begin{abstract}
In 2016, Bogor City was divided into 4 Areas of Planning of solid waste management. The chosen location was the Planning Area IV, because the location is a slum settlement. Solid waste management at this location is not good. Therefore, in order for solid waste to be managed and the reduction of solid waste when transported to the landfill requires $3 R$ based TPS that can manage and reduce the solid waste load in the landfill. The design of TPS assessment is prepared with the objective to identify the existing condition of TPS and the community behavior in managing solid waste around the existing TPS in order to be developed into TPS 3R. The design stage of TPS assessment begins with reference to Buku Pedoman Umum $3 R$ Pemukiman, dan Permen PU nomor 3 tahun 2013, collecting secondary data, 3 aspects grouping, namely location aspect, facility aspect, and activity aspect in TPS and divided into 5 sub aspect, 21 indicator and 34 question. In the assessment of TPS weights using Likert scale with weighted scale for TPS from the assessment result are 76-100 categories I (TPS 3R), 51 - 75 category 2 (TPS has high potential to TPS 3R), 26 - 50 category 3 (TPS is potential to be TPS 3R), 0 - 25 category IV (TPS has small potential to be TPS 3R). Whereas for PSM assessment have high value range (68 - 100), moderate (34 - 67), low (0 - 33). The number of respondents for PSM assessment is 20 house consisting of 8 questions, determined by Slovin formula with a population of 103,389 people and an error rate of $10 \%$. The number of TPS in the planning site is 10 unit.
\end{abstract}

Keywords: TPS, Indicator, Questionnaire, Region IV Planning, Bogor City. 


\section{PENDAHULUAN}

Lokasi pengembangan TPS menjadi TPS 3R adalah Wilayah Perencanaan IV Kota Bogor. Kota Bogor pada tahun 2016 dibagi menjadi 4 Wilayah Perencanaan sistem Pengelolaan Sampah. Lokasi Wilayah Perencanaan IV terdiri dari 8 kelurahan, dengan jumlah penduduk sebesar 103.389 jiwa. Wilayah Perencanaan IV ini dipilih karena karakteristik kepadatan penduduk tinggi, perumahan tidak teratur serta permukiman diwilayah ini adalah permukiman kategori kumuh ( DKP Kota Bogor 2016 ).

Pengelolaan sampah pada Wilayah perencanaan IV masih menggunakan sistem kumpul angkut - buang yang berujung pada jenis TPA open dumping ( DKP Kota Bogor 2016 ). Masalah dari sistem ini yaitu pada besarnya jumlah sampah yang diangkut ke TPA. TPA akan membutuhkan lahan yang luas dan dengan usia atau jangka waktu operasional yang lebih singkat. Masalah ini akan berdampak pada pencemaran lingkungan yang menjadi lokasi TPA. Untuk mencegah dampak tersebut, perlu adanya usaha untuk mereduksi sampah yang masuk ke TPA. Sampah yang lebih sedikit jumlahnya akan memperpanjang usia operasianal TPA dan mengurangi dampak pencemaran lingkungan apabila sampah yang masuk ke TPA hanya berupa residu saja.

Berdasarkan Undang - Undang RI No. 18 Tahun 2008 tentang Pengelolaan Sampah, penyelenggaraan pengelolaan sampah rumah tangga atau sampah sejenis sampah rumah tangga yaitu meliputi pengurangan dan penanganan sampah. Konsep 3R merupakan salah satu kegiatan pengurangan sampah yang sesuai dengan isi Undang - Undang RI No.18 Tahun 2008 tersebut. Selain dapat diaplikasikan di sumber sampah, konsep 3R juga dapat diaplikasikan pada skala wilayah system pengumpulan, salah satunya adalah TPS $3 R$. Adanya TPS 3R, sampah akan tereduksi jumlah dan komposisinya karena telah melalui beberapa proses seperti pemilahan, pengomposan, dan daur ulang. Telah terdapat beberapa TPS 3R di Kota Bogor, namun sebagian besar TPS yang ada masih berupa TPS lama dengan konsep kumpul - angkut - buang. TPS 3R tidak harus selalu berupa bangunan yang baru, tetapi juga dapat berupa pengembangan dari TPS yang lama dengan penambahan fasilitas dan kriteria lain sesuai dengan Permen PU No. 03/PRT/M/2013 tentang Penyelenggaraan Prasarana dan Sarana Persampahan dalam Penanganan Sampah Rumah Tangga dan Sejenis Sampah Rumah Tangga Oleh karena itu, perlu adanya studi evaluasi terhadap seluruh TPS eksisting yang ada sebelum kemudian dilakukan perencanaan menjadi TPS 3R.

Lokasi ini merupakan permukiman kategori kumuh, sampah dilokasi ini belum dikelola dengan baik. Sampah yang dihasilkan masih banyak yang di buang ke sungai, dibakar dan ke TPS tanpa adanya pengolahan lanjutan. Agar mengurangi beban sampah yang diangkut ke TPA, maka harus ada pengolahan lanjutan di tingkat TPS. Di lokasi ini jumlah TPS ada 10 ( DKP Kota Bogor 2016 ).

Sebagai langkah awal dalam perencanaan pengurangan sampah yang dibuang sembarangan dan mengurangi beban sampah di TPA, seluruh TPS di lokasi terpilih harus dilakukan evaluasi terhadap kondisi awal untuk mendapatkan data agar dapat dikembangkan menjadi TPS 3R. Metode evaluasi yang dilakukan adalah dengan cara membuat alat penilaian yang berupa alat penilaian TPS dan alat penilaian PSM untuk mengetahui kondisi eksisting TPS dan perilaku masyarakat dalam menangani sampah. 


\section{METODOLOGI}

\subsection{Persiapan}

Melakukan studi dari referensi mengenai teori, standar dan peraturan mengenai perencanaan TPS 3R yang akan digunakan sebagai acuan atau pedoman dalam penyusunan indikator pada alat penilaian TPS dan alat penilaian PSM.

\subsection{Pengumpulan Data sekunder}

Data demografi, geografi, topografi, dan social ekonomi wilayah perencanaan. Data ini didapatkan dari Badan Pusat Statistik Kota Bogor. Data ini berfungsi untuk mengetahui karakteristik dan gambaran umum kondisi Wilayah Perencanaan IV dan jumlah TPS yang berada di lokasi perencanaan.

\subsection{Penentuan Alat Penilaian}

\subsubsection{Alat Penilaian TPS}

\section{a. Penentuan Isi Alat Penilaian TPS}

Penentuan isi dalam penilaian TPS mengacu pada Buku Pedoman 3R permukiman Dinas Cipta Karya, dan Permen PU Nomor 3 tahun 2013 tentang Penyelenggaraan Prasarana dan Sarana Persampahan dalam Penanganan Sampah Rumah Tangga dan Sampah sejenis Sampah Rumah Tangga. Isi penilaian TPS dikelompokkan menjadi aspek, sub aspek, dan sub

- sub aspek serta beberapa pertanyaan.

\section{b. Penentuan Metode Penilaian Pertanyaan dalam Alat Penilaian TPS}

Penentuan metode penilaian pertanyaan di alat penilaian TPS ini bertujuan agar memudahkan perencana dalam melakukan penilaian hasil evaluasi di lapangan. Pertanyaan dalam penilaian TPS dapat berupa pilihan ganda, dan essai serta jawaban dengan menggunakan skala Likert.

\subsubsection{Alat Penilaian PSM}

\section{a. Penentuan Isi Alat Penilaian PSM}

Penentuan isi dalam alat penilaian PSM mengacu pada Undang - Undang RI No. 18 tahun 2008 tentang Pengelolaan Sampah dan Permen PU Nomor 3 tahun 2013 tentang Penyelenggaraan Prasarana dan Sarana Persampahan dalam Penanganan Sampah Rumah Tangga dan Sampah sejenis Sampah Rumah Tangga. Isi wawancara dikelompokkan menjadi aspek, sub aspek, dan sub - sub aspek serta beberapa pertanyaan.

\section{b. Penentuan Metode Penilaian Pertanyaan dalam Alat Penilaian PSM}

Penentuan metode penilaian pertanyan di wawancara ini bertujuan agar memudahkan perencana dalam melakukan penilaian hasil wawancara di lapangan. Pertanyaan dalam wawancara dapat berupa pilihan ganda, essai dan prosesnya bisa berupa wawancara, serta jawaban dapat menggunakan skala Likert. 


\subsection{Evaluasi Format Alat Penilaian TPS dan Alat Penilaian PSM}

Pada tahap ini, dilakukan evaluasi pada format alat penilaian TPS dan alat penilaian PSM bertujuan agar tidak ada kesalahan dalam tulisan dan susunan pertanyaan sebelum dilakukan penilaian langsung ke wilayah perencanaan.

\subsection{Pembobotan Nilai pada Alat Penilaian TPS dan Alat Penilaian PSM}

Pada tahap ini, dilakukan pembobotan nilai pada alat penilaian TPS dan alat penilaian PSM yang telah di dapatkan dari hasil lapangan, agar bertujuan mendapatkan nilai tertinggi dan terendah pada TPS eksisiting yang dapat dikembangkan menjadi TPS 3R yang direncanakan.

\subsection{Penentuan Jumlah Responden}

Tahap ini akan melakukan penentuan jumlah responden dan lokasi penyebarannya untuk alat penilaian PSM agar dapat mewakili data untuk perencanaan TPS 3R tersebut. Pada tahap ini diperlukan lokasi penyebaran yang tepat agar dapat mendapat informasi yang akurat. Penentuan jumlah menggunakan metode slovin (Soleh, 2005).

Metode slovin atau disebut metode random, pengukuran jumlah sampel berdasarkan metode ini menggunakan rumus:

$\mathrm{n}=\frac{N}{1+N\left(E^{2}\right)}$.

Dimana :

$\mathrm{n}$ adalah jumlah sampel

$\mathrm{N}$ adalah jumlah penduduk

$\mathrm{E}^{2}$ adalah tingkat eror $(1 \%, 2 \%, 3 \%, 5 \%$ atau $10 \%)$

Nilai tingkat eror yang dipilih adalah $10 \%$ karena keterbatasan biaya dan waktu dalam melakukan penelitian ini. 


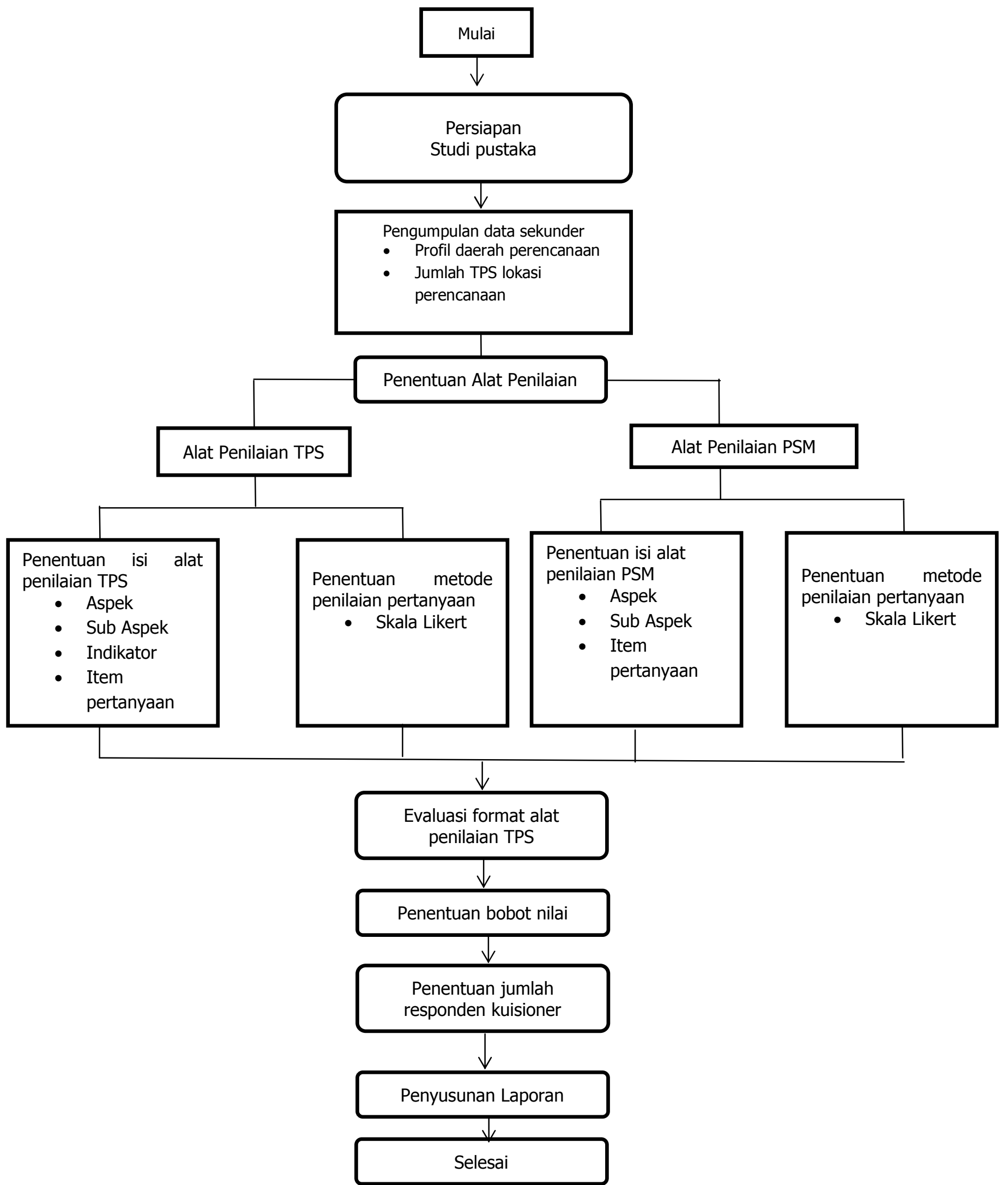

Gambar 1. Diagram Alir Langkah Kerja Perencanaan 


\section{ISI}

\subsection{Alat Penilaian}

\subsubsection{Alat Penilaian TPS}

Penentuan isi dalam alat penilaian TPS mengacu pada Buku Pedoman 3R permukiman Dinas Cipta Karya, dan Permen PU Nomor 3 Tahun 2013 tentang Penyelenggaraan Prasarana dan Sarana Persampahan dalam Penanganan Sampah Rumah Tangga dan Sampah Sejenis Sampah Rumah Tangga. Jawaban pada alat penilaian TPS menggunakan skala Likert agar memudahkan dalam memberikan pilihan jawaban saat di lapangan. Mengacu pada peraturan tersebut maka alat penilaian TPS dikelompokkan menjadi 3 aspek, yaitu lokasi, fasilitas, dan kegiatan. Berdasarkan 3 aspek tersebut dibagi menjadi 5 sub aspek, yaitu lokasi, fasilitas utama, fasilitas pelengkap, bangunan TPS, dan operasional di TPS. Dari 5 sub aspek tersebut dikembangkan menjadi 21 indikator dan 34 pertanyaan.

- Aspek Lokasi

Pada aspek lokasi dikembangkan menjadi 1 sub aspek, 5 indikator dan 7 item pertanyaan yang dapat mewakili aspek lokasi tersebut, dengan mengacu pada peraturan - peraturan yang menjadi studi literatur dalam pengerjaan penelitian ini.

Tabel 1. Alat Penilaian TPS Aspek Lokasi

\begin{tabular}{|c|c|c|}
\hline Aspek & Sub Aspek & Indikator \\
\hline \multirow{5}{*}{ Lokasi } & \multirow{5}{*}{ Lokasi } & jarak lokasi TPS terhadap wilayah pelayanan \pm 500 meter, semakin dekat semakin baik \\
\hline & & $\begin{array}{l}\text { lahan merupakan milik pemerintah daerah ( PEMDA ) atau lahan yang sudah di hibahkan } \\
\text { oleh pemiliknya atau milik perorangan }\end{array}$ \\
\hline & & Pengelola TPS \\
\hline & & $\begin{array}{l}\text { luas lahan minimal harus lebih besar atau sama dengan } 200 \mathrm{~m}^{2} \text {, semakin luas semakin } \\
\text { baik }\end{array}$ \\
\hline & & $\begin{array}{l}\text { akses jalan masuk ke TPS harus bisa dilalui oleh truck pengangkut, semakin lebar jalan } \\
\text { semakin baik }\end{array}$ \\
\hline
\end{tabular}

Sumber : Hasil Analisa, 2017

- Aspek Fasilitas

Pada aspek fasilitas dikembangkan menjadi 3 sub aspek, 11 indikator, dan 22 item pertanyaan yang dapat mewakili aspek fasilitas tersebut, dengan mengacu pada peraturan peraturan yang menjadi studi literatur dalam pengerjaan penelitian ini.

Tabel 2. Alat Penilaian TPS Aspek Fasilitas

\begin{tabular}{|c|c|c|}
\hline Aspek & Sub Aspek & Indikator \\
\hline \multirow{11}{*}{ Fasilitas } & \multirow{3}{*}{ Fasilitas Utama } & $\begin{array}{l}\text { area penampung sampah baik itu berupa kontainer atau lahan kosong, serta } \\
\text { kondisi dan jenis lantai di TPS }\end{array}$ \\
\hline & & area pemilahan sampah di TPS \\
\hline & & area pengolahan sampah di TPS \\
\hline & \multirow{4}{*}{ Bangunan TPS } & atap penutup untuk seluruh TPS \\
\hline & & dinding penghalang sekitar TPS \\
\hline & & gerbang penutup akses masuk TPS \\
\hline & & kantor operasional di TPS \\
\hline & \multirow{4}{*}{$\begin{array}{l}\text { Fasilitas } \\
\text { Penunjang }\end{array}$} & instalasi air bersih yang digunakan untuk operasional di TPS tersebut. \\
\hline & & $\begin{array}{l}\text { saluran drainase di area TPS yang bertujuan untuk mengalirkan air lindi serta air } \\
\text { hujan,agar sampah tidak bercampur dengan air. }\end{array}$ \\
\hline & & aliran listrik yang digunakan untuk operasional di TPS \\
\hline & & $\begin{array}{l}\text { barrier ( pagar tanaman hidup ), agar estetika TPS terlihat indah serta dapat } \\
\text { menyerap bau yg dihasilkan oleh sampah di TPS serta menambah fungsi isolasi } \\
\text { TPS }\end{array}$ \\
\hline
\end{tabular}

Sumber : Hasil Analisa, 2017

[Perancangan Penilaian Untuk Pengembangan TPS Menjadi TPS 3RDi Wilayah Perencanaan IV Kota Bogor] -7 
- Aspek Kegiatan

Pada aspek kegiatan dikembangkan menjadi 1 sub aspek, 5 indikator, dan 5 item pertanyaan yang dapat mewakili aspek lokasi tersebut, dengan mengacu pada peraturan - peraturan yang menjadi studi literatur dalam pengerjaan penelitian ini.

Tabel 3. Alat Penilaian TPS Aspek Kegiatan

\begin{tabular}{|c|c|c|}
\hline Aspek & Sub Aspek & Indikator \\
\hline \multirow{5}{*}{ Kegiatan } & \multirow{5}{*}{ Operasional } & $\begin{array}{l}\text { akses jalan masuk ke TPS harus bisa dilalui oleh truck pengangkut, semakin } \\
\text { lebar jalan semakin baik }\end{array}$ \\
\hline & & area pemilahan sampah di TPS \\
\hline & & area pengolahan sampah di TPS \\
\hline & & kantor operasional di TPS \\
\hline & & gerbang di akses TPS \\
\hline
\end{tabular}

Sumber : Hasil Analisa, 2017

\subsubsection{Alat Penilaian PSM}

Penentuan isi dalam alat penilaian PSM mengacu pada Undang - Undang RI No. 18 tahun 2008 tentang Pengelolaan Sampah, dan Permen PU nomor 3 tahun 2013 tentang Penyelenggaraan Prasarana dan Sarana Persampahan dalam Penanganan Sampah Rumah Tangga dan Sampah sejenis Sampah Rumah Tangga. Mengacu pada peraturan tersebut maka isi alat penilaian PSM dikelompokkan menjadi 3 aspek, yaitu peran serta masyarakat, retribusi/pembiayaan, dan kelembagaan. Berdasarkan 3 aspek tersebut didapat 6 sub aspek, dan 8 item pertanyaan.

Tabel 4. Alat Penilaian Wawancara TPS

\begin{tabular}{|c|c|}
\hline Aspek & Sub Aspek \\
\hline \multirow{4}{*}{ Peran Serta Masyarakat } & Prilaku masyarakat terhadap pemilahan sampah di sumber \\
\hline & Pengolahan sampah organik di sumber \\
\hline & Pemilahan sampah anorganik di sumber \\
\hline & Partisipasi masyarakat terhadap pengelolaan di TPS \\
\hline \multirow{2}{*}{$\begin{array}{c}\text { Retribusi / Pembiayaan } \\
\text { Kelembagaan }\end{array}$} & $\begin{array}{l}\text { Seberapa sanggup dan mau masyarakat dalam berkontribusi membayar } \\
\text { iuran untuk pengelolaan sampah di TPS }\end{array}$ \\
\hline & lembaga pengelola di TPS \\
\hline
\end{tabular}

Sumber : Hasil Analisa, 2017

\subsection{Pembobotan Nilai}

Pembobotan nilai untuk pengembangan TPS dilakukan dengan cara teknis dan non teknis. Secara teknis dengan hasil alat penilaian TPS dan non teknis dengan hasil alat penilaian PSM.

- Alat penilaian TPS

Pembobotan pada alat penilaian TPS menggunakan skala Likert yang sudah dirancang sebelumnya, score total hasil dari skala Likert untuk alat penilaian TPS sebesar 96 lalu dikalikan dengan setiap nilai maksimum item pertanyaan sehingga didapatkan score terbesar 100 .

Jadi standar penilaian TPS ada 4 kategori :

a. Kategori I sebesar $76-100$ (Sudah menjadi TPS 3R)

b. Kategori II sebesar $51-75$ (Berpotensi tinggi menjadi TPS 3R)

c. Kategori III sebesar 26-50 (Berpotensi sedang menjadi TPS 3R)

d. Kategori IV sebesar 0 - 25 (Berpotensi rendah menjadi TPS 3R) 
Berikut ini adalah Tabel tentang pembobotan pada alat Penilaian TPS :

Tabel 5. Data Pembobotan Alat Penilaian TPS

\begin{tabular}{cccccc}
\hline Aspek & $\begin{array}{c}\text { Bobot } \\
\text { Nilai } \\
\text { aspek }\end{array}$ & Sub aspek & $\begin{array}{c}\text { Bobot } \\
\text { Nilai } \\
\text { Sub } \\
\text { aspek }\end{array}$ & $\begin{array}{c}\text { Jumlah } \\
\text { pertanyaan } \\
\text { dalam 1 } \\
\text { sub aspek }\end{array}$ & $\begin{array}{c}\text { Bobot } \\
\text { maksimal Item } \\
\text { pertanyaan } \\
\text { untuk setiap } \\
\text { sub aspek }\end{array}$ \\
\hline Lokasi & 35 & Lokasi & 35 & 6 & 5,83 \\
\hline \multirow{2}{*}{ Fasilitas } & 55 & Fasilitas Utama & 35 & 10 & 3,5 \\
\cline { 3 - 6 } & 10 & Fasilitas Pelengkap & 10 & 7 & 2 \\
\hline Kegiatan & 10 & Bangunan TPS & 10 & 5 & 1,42 \\
\hline Total & 100 & Operasional & 10 & 5 & 2 \\
\hline
\end{tabular}

Sumber : Hasil Analisa, 2017

- Alat penilaian PSM

Pada alat penilaian PSM terdapat 3 aspek, 6 sub aspek, dan 8 item pertanyaan. Pada penentuan isi jawaban pertanyaan menggunakan skala Likert untuk aspek retribusi, aspek kelembagaan, dan aspek peran serta masyarakat dalam penentuan jawabannya. Total score untuk jawaban pertanyaan skala Likert berjumlah 16. Maka dilakukan pembobotan nilai di pengolahan data supaya di dapat standar alat penilaian PSM. Setelah melakukan pembobotan nilai untuk setiap aspek, sub aspek dan item pertanyaan dalam alat penilaian PSM, maka akan didapat jumlah total nilai rata - rata responden. Untuk data pembobotan nilai untuk alat penilaian PSM dapat dilihat pada tabel 6 . berikut ini :

Tabel 6. Pembobotan Alat Penilaian PSM

\begin{tabular}{|c|c|c|c|c|c|}
\hline Aspek & $\begin{array}{c}\text { Bobot Nilai } \\
\text { aspek }\end{array}$ & Sub aspek & $\begin{array}{c}\text { Bobot } \\
\text { Nilai } \\
\text { Sub } \\
\text { aspek }\end{array}$ & $\begin{array}{c}\text { No } \\
\text { pertanyaan } \\
\text { dan } \%\end{array}$ & $\begin{array}{c}\text { Bobot } \\
\text { masimal } \\
\text { Item } \\
\text { pertanyaan }\end{array}$ \\
\hline \multirow{4}{*}{$\begin{array}{l}\text { Peran Serta } \\
\text { Masyarakat }\end{array}$} & \multirow{4}{*}{50} & $\begin{array}{l}\text { Prilaku masyarakat terhadap } \\
\text { pemilahan sampah di sumber }\end{array}$ & 12,5 & $1(25)$ & 12,5 \\
\hline & & $\begin{array}{l}\text { Pengolahan sampah organik } \\
\text { di sumber }\end{array}$ & 12,5 & $2(25)$ & 12,5 \\
\hline & & $\begin{array}{l}\text { Pemilahan sampah anorganik } \\
\text { di sumber }\end{array}$ & 12,5 & $3(25)$ & 12,5 \\
\hline & & $\begin{array}{l}\text { Partisipasi } \quad \text { masyarakat } \\
\text { terhadap pengelolaan di TPS }\end{array}$ & 12,5 & $4(25)$ & 12,5 \\
\hline \multirow{3}{*}{$\begin{array}{l}\text { Retribusi / } \\
\text { Pembiayaan }\end{array}$} & \multirow{3}{*}{30} & \multirow{3}{*}{$\begin{array}{lr}\text { Seberapa sanggup dan mau } \\
\text { masyarakat } & \text { dalam } \\
\text { berkontribusi } & \text { membayar } \\
\text { iuran untuk } & \text { pengelolaan } \\
\text { sampah di TPS } & \end{array}$} & \multirow{3}{*}{30} & $5(30)$ & 9 \\
\hline & & & & $6(30)$ & 9 \\
\hline & & & & $7(40)$ & 12 \\
\hline Kelembagaan & 20 & lembaga pengelola di TPS & 20 & $8(100)$ & 20 \\
\hline Total & 100 & Total & 100 & & 100 \\
\hline
\end{tabular}

Sumber : Hasil Analisa, 2017

Untuk bobot maksimal item pertanyaan untuk setiap sub aspek di dapat dari pembagian bobot nilai sub aspek dibagi persentase pertanyaan dalam satu sub aspek. Setelah dilakukan pembobotan pada aspek, sub aspek dan item pertanyaan selanjutkan dilakukan pengelompokan hasil penilaian PSM berdasarkan range nilai PSM yang dibuat. Range nilai PSM dapat dilihat pada tabel 7. berikut ini : 
Tabel 7. Range nilai PSM

\begin{tabular}{cc}
\hline & RANGE NILAI PSM \\
\hline TINGGI & $68-100$ \\
SEDANG & $34-67$ \\
RENDAH & $0-33$ \\
\hline
\end{tabular}

Sumber : Hasil Analisa, 2017

\subsection{Penentuan Jumlah Responden}

Tahap ini perencana melakukan penentuan jumlah responden untuk alat penilaian TPS dan alat penilaian PSM agar dapat mewakili data untuk perencanaan TPS 3R tersebut. Pada tahap ini perencana menggunakan metode slovin dengan perhitungan seperti berikut :

$$
n=\frac{103.389 \text { jiwa }}{1+103.389 \text { jiwa }\left(10 \%^{2}\right)}=99,9 \text { jiwa. }
$$

Banyaknya orang yang dibutuhkan untuk sampel adalah 100 jiwa. Setelah dikonversi dengan banyaknya jiwa dalam $1 \mathrm{KK}$ (5 jiwa/KK) maka didapat $20 \mathrm{KK}$ atau rumah. Jumlah sampel yang dipilih adalah berdasarkan metode Slovin yaitu sebanyak 20 rumah. Jumlah TPS yang ada pada lokasi perencanaan berjumlah 10 TPS.

\section{KESIMPULAN}

Perancangan alat penilaian ini, mengacu pada Buku Pedoman 3R permukiman Dinas Cipta Karya, dan Permen PU nomor 3 tahun 2013 tentang Penyelenggaraan Prasarana dan Sarana Persampahan dalam Penanganan Sampah Rumah Tangga dan Sampah sejenis Sampah Rumah Tangga dan Undang - Undang RI No. 18 tahun 2008 tentang Pengelolaan Sampah. Alat penilaian TPS terdiri dari 3 aspek utama yaitu, aspek lokasi, fasilitas, dan kegiatan. Serta terdapat 5 sub aspek, yaitu lokasi, fasilitas utama, bangunan TPS, fasilitas pelengkap, dan operasional di TPS. Dari sub aspek dikembangkan menjadi 21 indikator dan 34 item pertanyaan. Pada alat penilaian PSM terdiri dari 3 aspek besar, yaitu peran serta masyarakat, pembiayaan, dan kelembagaan. Terdapat 5 sub aspek dan 8 item pertanyaan. Skala pembobotan untuk TPS dari hasil penilaian TPS adalah Kategori I sebesar 76 - 100 (Sudah menjadi TPS 3R), Kategori II sebesar 51 - 75 (Berpotensi tinggi menjadi TPS 3R), Kategori III sebesar 26 - 51 (Berpotensi sedang menjadi TPS 3R), dan Kategori IV sebesar $0-25$ (Berpotensi rendah menjadi TPS 3R). Sedangkan untuk penilaian PSM mempunyai range nilai tinggi $(68-100)$, sedang $(34-67)$, rendah $(0-33)$. Jumlah responden untuk penilaian PSM sebanyak 20 rumah dan jumlah TPS eksisting yang ada pada lokasi perencanaan berjumlah 10 TPS. 


\section{DAFTAR RUJUKAN}

Peraturan Pemerintah, Nomor 18. 2008.Tentang Pengelolaan Sampah

Peraturan Menteri Pekerjaan Umum,Nomor 3. 2013.Tentang Penyelenggaraan Prasarana Dan Sarana Persampahan Dalam Penanganan Sampah Rumah Tangga Dan Sampah Sejenis Sampah Rumah Tangga.

Damanhuri, P. E. (2010). Diktat Kuliah TL-3104. Bandung.

Buku Pedoman 3R Permukiman. Cipta Karya.2014

Badan Pusat Statistik Kota Bogor. "Kota Bogor dalam Angka", 2016.

Dinas Kebersihan dan Pertamanan Kota Bogor, 2016

Soleh, A. Z. (2005). IImu Statistika Pendekatan Teoritis dan Aplikatif disertai contoh penggunaan SPSS. Bandung: REKAYASA SAINS Bandung. 